\title{
Aplikasi Deteksi Tumpahan Minyak dengan Interpretasi Citra Satelit Landsat 8
}

\author{
Veranita Lamrotua Sihombing, I Dewa Nyoman Nurweda Putra, Gusti Made Arya Sasmita \\ Program Studi Teknologi Informasi, Fakultas Teknik, Universitas Udayana \\ Bukit Jimbaran, Bali, Indonesia, telp. (0361) 701806 \\ e-mail: veranitak@gmail.com, nurweda14@unud.ac.id, aryasasmita88@gmail.com
}

\begin{abstract}
Abstrak
Tumpahan minyak akibat kebocoran pipa pada tahun 2015 menyebarkan minyak di sepanjang perairan cilacap dan menyebabkan tercemarnya perairan cilacap yang mengancam kelangsungan biota hidup di sekitarnya. Tumpahan minyak berhasil dideteksi oleh satelit Landsat 8 dan melalui sistem penginderaan jauh dapat diketahui persebaran tumpahan minyak untuk mempermudah proses penanggulangan dengan memperhitungkan Oil Spill Dispersant yang dibutuhkan. Tujuan dari penelitian ini adalah merancang sebuah aplikasi penginderaan jauh untuk menghitung luas persebaran tumpahan minyak dengan menerima input berupa data citra Landsat 8 dan metadata. Pengolahan citra menggunakan dua algoritma untuk membandingkan perbedaan hasil visualisasi yang di tampilkan. Algoritma yang digunakan adalah algoritma Thresholding dan Oil Spill Index. Aplikasi bekerja secara otomatis melakukan pengolahan citra untuk menghasilkan visualisasi dan persebaran tumpahan minyak.
\end{abstract}

Kata Kunci : Oil Spill Index, Algoritma Thresholding, Tumpahan Minyak

\begin{abstract}
Oil spills due to pipeline leakage in 2015 spread oil along Cilacap waters and caused contamination of Cilacap waters which threatened the survival of living biota in the vicinity. Oil spill was successfully detected by Landsat 8 satellite and through the remote sensing system can be known the distribution of oil spills to facilitate the countermeasure process by calculating the required Oil Spill Dispersant. The purpose of this study was to design a remote sensing application to calculate the spread area of an oil spill by receiving input in the form of Landsat 8 image data and metadata. Image processing uses two algorithms to compare the differences in visualization results displayed. The algorithms used are Thresholding and Oil Spill Index algorithms. The working application automatically performs image processing to produce visualization and distribution of oil spills.
\end{abstract}

\section{Keywords: Oil Spill Index, Thresholding Algorithm,Oil Spill}

\section{Pendahuluan}

Kasus kebocoran ladang minyak terjadi pada tanggal 20 Mei 2015, berdasarkan hasil yang dirilis Pertamina Refinery Unit (RU) IV Cilacap, telah terjadi kerusakan fasilitas bongkar muat cruide oil di Single Point Mooring (SPM) yang terletak 16 mil laut sebelah selatan pantai Cilacap yang menyebabkan adanya tumpahan minyak disekitar teluk penyu Cilacap [1]. Deteksi penyebaran tumpahan minyak tersebut dapat diketahui dengan berbagai macam pendekatan, salah satunya adalah pemanfaatan sistem penginderaan jauh (remote sensing) dengan melihat nilai index vegetasi [2]. Penelitian yang berkaitan dengan penginderaan jauh umumnya dilakukan dengan perhitungan vegetasi manual dan menggunakan aplikasi pihak ketiga sebagai aplikasi pengolah citra [3].

Penelitian sebelumnya sebagai bahan acuan penelitian ini telah dilakukan Muhammad Sudibjo pada Tahun 2013 dengan merancang aplikasi yang dapat menerima input berupa data penginderaan jauh yaitu citra Satelit Landsat $8 \mathrm{OLI}$ and TIRS dan file metadata [4]. Penelitian yang dilakukan oleh Qianguo Xing pada Tahun 2015 memanfaatkan data citra Landsat-7 ETM dan Landsat-5 TM. Teknik penginderaan jauh yang digunakan adalah teknik deteksi inframerah (Infrared remote sensing techniques) untuk mengidentifikasi tempat awal kebocoran minyak mentah dan penyebarannya di laut [5]. Penelitian A.A.Gede Putra pada Tahun 2011 melakukan klasifikasi secara visual meliputi pendeteksian area terpapar, pengukuran area terpapar, dan 
klasifikasi menggunakan citra satelit Modis untuk mengetahui sebaran minyak di Laut [6]. Penelitian yang dilakukan oleh Muhammad Sudibjo pada Tahun 2013 menggunakan empat algoritma untuk membandingkan hasil perhitungan yang lebih akurat dalam mendeteksi keberadaan tumpahan minyak yaitu Oil Spill Index, Fluorescence Index, Principal Component Analysis (PCA), Normalized Difference Vegetation Index (NDVI) [7].

Penelitian Rancang Bangun Aplikasi Deteksi Tumpahan Minyak Interpretasi Citra Satelit Landsat 8 menggunakan kombinasi dua algoritma dengan satu data citra yaitu penggunaan algoritma Thresholding dan Oil Spill Index untuk melakukan pengolahan data citra satelit Landsat 8. Perbandingan hasil deteksi tumpahan minyak dengan Algoritma Oil Spill Index dan algoritma Thresholding dapat menghasilkan informasi sebaran tumpahan minyak di laut tanpa perlu turun ke lapangan untuk melakukan penelitian. Rancang bangun aplikasi ini juga di dasarkan karena belum adanya aplikasi yang berdiri sendiri untuk menentukan luas sebaran tumpahan minyak sehingga memudahkan peneliti dalam menghitung dan mengontrol luas tumpahan minyak.

\section{Metodologi Penelitian}

Gambaran umum sistem Rancang Bangun Aplikasi Deteksi Tumpahan Minyak Dengan Interpretasi Citra Satelit Landsat 8 pada Gambar 1 dirancang untuk membangun aplikasi dengan alur kerja yang baik.

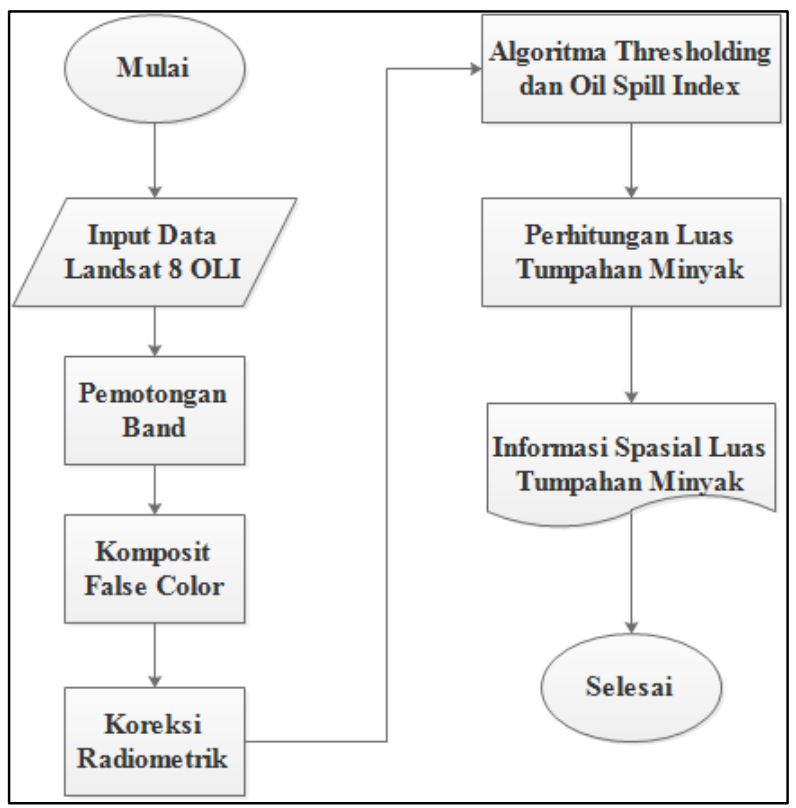

Gambar 1. Gambaran Umum Sistem

Alur kerja aplikasi di mulai dengan tahap pertama yaitu melakukan input citra ke dalam sistem, data citra adalah data citra Landsat 8 dalam format Tiff. Tahap kedua adalah melakukan pemotongan citra untuk mendapatkan daerah yang lebih spesifik. Tahap ketiga adalah komposit false color yang berguna untuk menampilkan warna kontras, untuk membedakan objek yang ada di tempat. Tahap keempat adalah Processing dengan melakukan koreksi radiometric terlebih dahulu dan tahap Kelima adalah melakukan perhitungan Algoritma Thresholding dan Oil Spill Index. Output yang dihasilkan aplikasi adalah peta penyebaran tumpahan minyak dan luas daerah yang terkena tumpahan minyak.

\section{Kajian Pustaka}

\subsection{Satelit Landsat 8}

Satelit Landsat merupakan salah satu satelit yang digunakan untuk mengamati permukaan bumi. Landsat 8 memiliki sensor dengan rentang yang berbeda masing-masing memiliki karakteristik yang ditentukan oleh frekuensi spektrum elektromagnetik. Setiap rentang tersebut dikenal dengan istilah band. Secara keseluruhan Landsat 8 memiliki 11 band [8]. Nilai piksel pada citra satelit komersil menunjukkan paparan dari permukaan bumi dalam bentuk 
Digital Number $(D N)$ yang dikalibrasi ke suatu rentang nilai. Konversi DN ke dalam paparan nyata perlu dilakukan untuk analisis komparatif dari beberapa citra yang diambil oleh sensor yang berbeda. Citra Landsat 8 yang diperlukan dalam melakukan penelitian deteksi tumpahan minyak. Terdapat tiga band yaitu Band 4- Visible Red Band yang bermanfaat untuk mendiskriminasikan lereng vegetasi, Band 3-Visible Green Band yang bermanfaat untuk menekankan vegetasi puncak yang berguna untuk menilai kekuatan tanaman dan Band 3-Visible Blue Band yang bermanfaat untuk Pemetaan batimetri dan membedakan tanah Band 5- Visible NIR Band yang bermanfaat untuk menekankan konten biomassa dan garis pantai.

\subsection{Algoritma Thresholding}

Algoritma Thresholding adalah proses pengubahan gambar input grayscale ke citra bilevel dengan menggunakan ambang optimal. Thresholding by Index membandingkan RGB nilai merah dan biru dan mendapatkan nilai perbedaan [(biru-merah) / (biru + merah)]. Nilai BRT akan dapat dilacak dengan warna air, tanah, minyak di daerah tumpahan minyak. Produk hidrokarbon memiliki sifat fluoresensi dimana memancarkan cahaya ketika terkena ultraviolet atau beberapa sinar tampak. Sehingga dengan algoritma thresholding (fluorescence Index) dapat diketahui keberadaan senyawa hidrokarbon [9].

$$
\text { Thresholding }=\frac{\text { Visible Blue Band-Visible Red Band }}{\text { Visible Blue Band-Visible Red Band }}
$$

Citra Landsat 8 spektrum biru (Blue) berada pada kanal 2 dan spektrum merah (Red) terdapat pada kanal 4. Semakin tinggi komponen hidrokarbon maka nilai thresholding juga akan semakin besar [10].

\subsection{Oil Spill Index}

Algoritma Oil Spill Index memiliki prinsip rasio kanal, yaitu membandingan selisih dan jumlah dari kanal 3 (Band Green) dan kanal 4 (Band Red) dari Landsat 8 yang dinormalisasikan dengan kanal 2 (Band Blue) sehingga menghasilkan nilai yang berbeda antara minyak dan bukan minyak [11]. Algoritma tersebut dapat dituliskan sebagai berikut:

$$
\text { Oil Spill Index }=\frac{(\text { Green Band/Blue Band })-(\text { Green Band } / \text { Blue Band })}{(\text { Green Band } / \text { Blue Band })+(\text { Green Band } / \text { Blue Band })}
$$

Oil Spill Index mampu memberikan penampakan yang jelas pada daerah tumpahan minyak dan memberikan kontras warna di daerah tersebut, algoritma ini menggunakan panjang gelombang pendek seperti band biru yang mempunyai kemampuan lebih baik mengidentifikasi material biogenic.Proses perhitungan luas tumpahan minyak dengan algoritma Oil Spill Index.

\section{Hasil dan Pembahasan}

Aplikasi yang dirancang adalah aplikasi berbasis desktop. GUI atau Graphical User Interface aplikasi dibuat sederhana agar mudah digunakan oleh user. Halaman utama aplikasi Rancang Bangun Aplikasi Deteksi Tumpahan Minyak dengan Interpretasi Citra Landsat 8, terdiri dari tiga menu utama yang merupakan proses-proses yang dapat dijalankan di dalam aplikasi. Cropping digunakan untuk membuka jendela pemotongan gambar, Composite digunakan untuk membuka jendela menu komposit dan Analisis digunakan untuk membuka jendela perhitungan menggunakan algoritma Thresholding dan Oill Spill Index. 


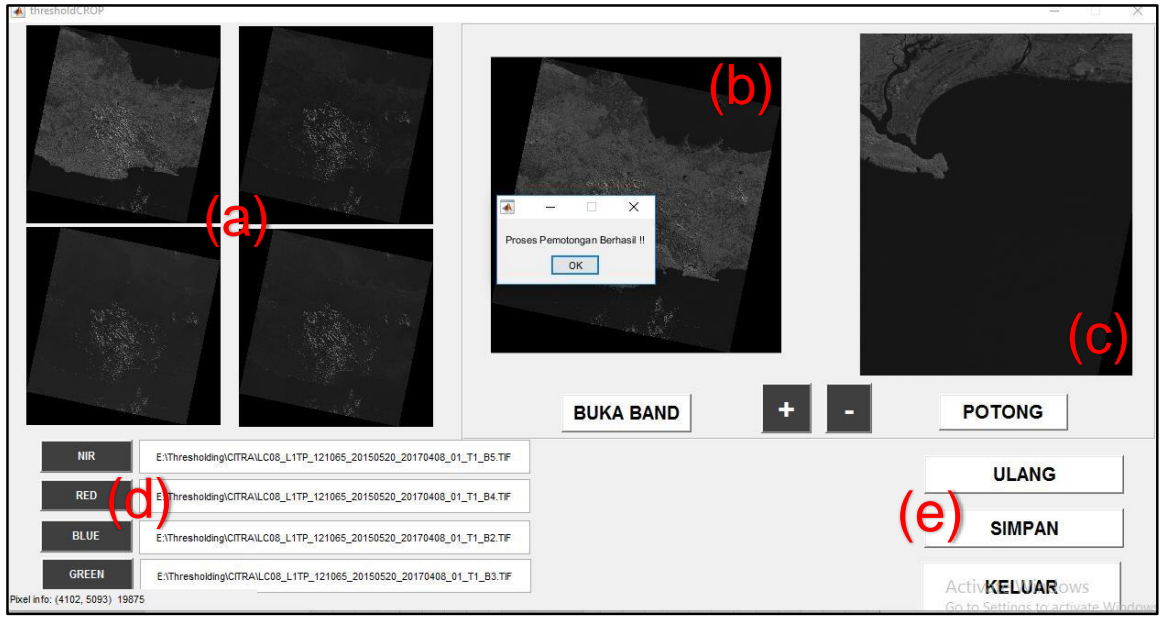

Gambar 2. Proses Cropping(a)Citra Mentah, (b) Citra Nir, (c) Hasil Cropping, (d) Input Band, (e) Fungsi Tambahan

Terdapat beberapa proses yang terjadi pada menu cropping yaitu proses meng-inputkan citra Visible NIR Band, Visible Red Band, Visible Green Band, dan Visible Blue Band, proses menampilkan direktori penyimpanan citra Visible NIR Band, Visible Red Band, Visible Green Band, dan Visible Blue Band, proses menampilkan citra Visible NIR Band, Visible Red Band, Visible Green Band, dan Visible Blue Band ke axes pada Panel Gambar, proses menampilkan Visible NIR Band pada Panel Hasil, proses cropping atau pemotongan citra dan proses penyimpanan citra yang telah di potong. Gambar 2(a) merupakan tampilan dari Visible NIR Band, Visible Red Band, Visible Green Band, dan Visible Blue Band yang telah di input-kan. Gambar 2(b) merupakan tampilan Visible NIR Band yang lebih besar sebagai acuan pemotongan citra. Gambar 2(c) merupakan tampillan hasil citra yang telah dipotong. Gambar 2(d) merupakan tampilan direktori penyimpanan citra. Gambar 2(e) merupakan fungsi tambahan pada menu cropping berupa tombol simpan, keluar dan pembersihan jendela menu cropping.

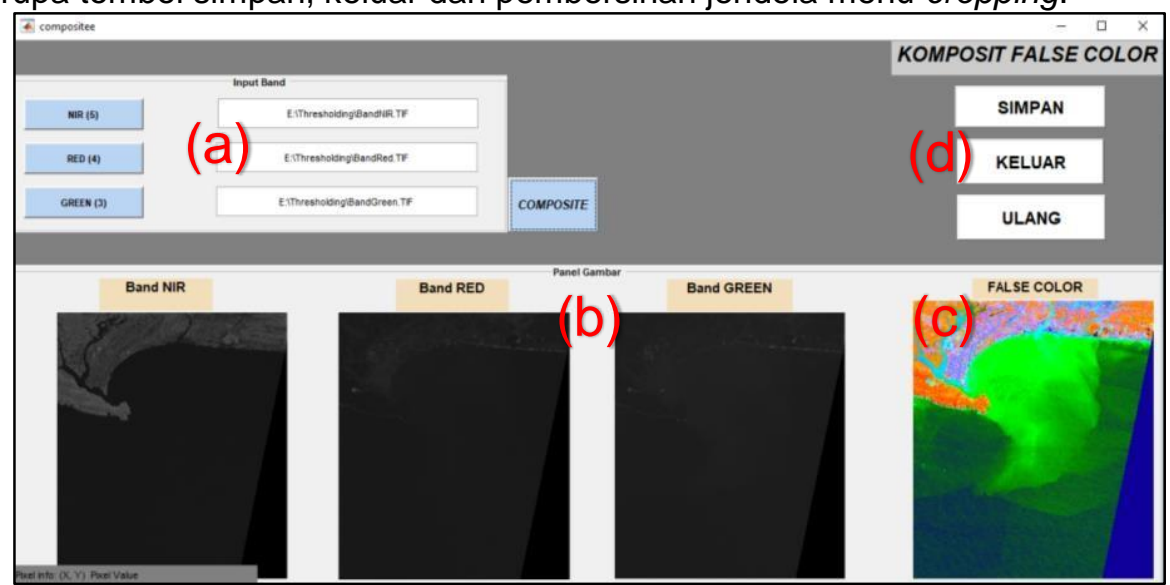

Gambar 3. Composite False Color (a) Input Band, (b) Citra Cropping, (c) False Color, (d) Fungsi Tambahan

Terdapat beberapa proses yang terjadi pada menu composite yaitu proses meng-inputkan citra Visible NIR Band, Visible Red Band dan Visible Green Band, proses menampilkan direktori penyimpanan citra Visible NIR Band, Visible Red Band dan Visible Green Band, proses menampilkan citra Visible NIR Band, Visible Red Band dan Visible Green Band ke axes pada Panel Gambar, proses composite atau komposit false color citra dan proses penyimpanan citra yang telah di komposit. Gambar 3(a) merupakan tampilan direktori penyimpanan citra.Gambar 3(b) merupakan tampilan dari Visible NIR Band, Visible Red Band dan Visible Green Band yang telah di input-kan. Gambar 3(c) tampilan hasil proses komposit false color. Gambar 3(d) 
merupakan fungsi tambahan pada menu composite berupa tombol simpan, keluar dan pembersihan jendela menu composite.

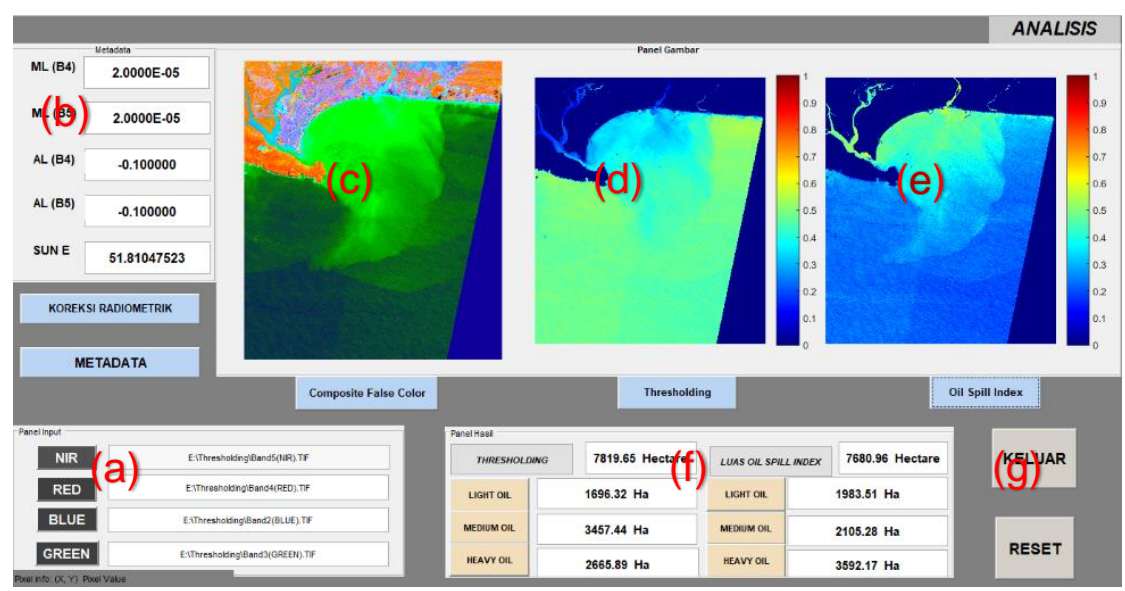

Gambar 4. Proses Analisis (a) Input Band, (b) Metadata,(c) False Color,

(d) Thresholding, (e) Oil spill Index

Terdapat beberapa proses yang terjadi pada menu Analisis yaitu proses meng-input-kan citra Visible NIR Band, Visible Red Band, Visible Green Band, dan Visible Blue Band, proses menampilkan direktori penyimpanan citra Visible NIR Band, Visible Red Band, Visible Green Band, dan Visible Blue Band, proses menampilkan citra Visible NIR Band, Visible Red Band, Visible Green Band, dan Visible Blue Band ke axes pada Panel Gambar, proses menampilkan info metadata pada Panel Metadata, proses menampilkan composite false color, proses menampilkan hasil pengolahan citra dengan algoritma Oil Spill Index, proses menampilkan hasil pengolahan citra menggunakan algoritma Thresholding, proses menampilkan sebaran tumpahan minyak berdasarkan kategori masing-masing. Gambar 4(a) menampilkan direktori Visible NIR Band, Visible Red Band, Visible Green Band, dan Visible Blue Band yang telah di input-kan. Gambar 4(b) menampilkan informasi metadata yang telah di input-kan. Gambar 4(c) menampilkan hasil composite false color. Gambar 4(d) menampilkan hasil visualisasi pengolahan citra dengan algoritma Oil Spill index. Gambar 4(e) menampilkan hasil visualisasi pengolahan citra dengan algoritma Thresholding. Gambar 4(f) melakukan perhitungan luas tumpahan minyakdan Gambar 4(g) merupakan fungsi tambahan pada menu cropping berupa tombol keluar dan pembersihan jendela menu Analisis.
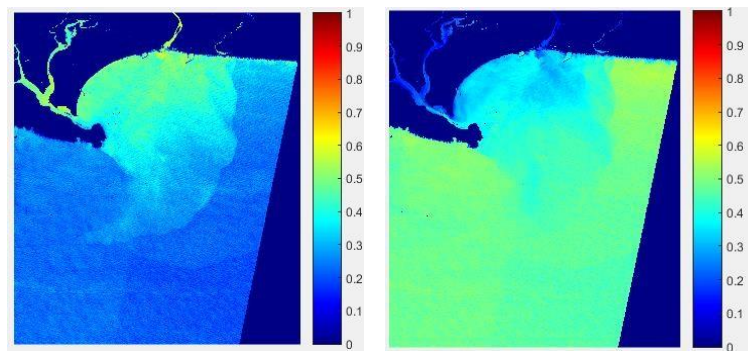

Gambar 5. Citra Hasil (a) Oil Spill Index, (b) Thresholding

Pengolahan citra menggunakan algoritma Oil Spill Index menghasilkan sebuah citra pada Gambar 5(a). Nilai tertinggi digambarkan dengan warna merah dan nilai terendah digambarkan dengan nilai biru. Terdapat beberapa perbedaan warna objek yang dapat dilihat jelas. Fungsi NDVI telah menjadikan darat bernilai 0 agar objek pengolahan terfokus di bagian laut. Warna minyak biru muda dapat dilihat terlihat mengapung diatas permukaan laut dan warna laut lebih biru tua mendekati nilai 0. Dengan grafik warna dan nilai dapat dilihat bahwa nilai tumpahan minyak lebih besar dari air laut yaitu sekitar $0.36-0.42$. Pengolahan citra menggunakan algoritma Thresholding menghasilkan sebuah citra pada Gambar 5(b). Nilai tertinggi digambarkan dengan warna merah dan nilai terendah digambarkan dengan nilai biru. Terdapat beberapa perbedaan warna objek yang dapat dilihat jelas. Fungsi NDVI telah 
menjadikan darat bernilai 0 agar objek pengolahan terfokus di bagian laut. Warna minyak biru muda dapat dilihat terlihat mengapung diatas permukaan laut dan warna laut lebih biru tua mendekati nilai 0 . Dengan grafik warna dan nilai dapat dilihat bahwa nilai tumpahan minyak lebih besar dari air laut yaitu sekitar 0.35-0.41. Proses perhitungan luas perseparan tumpahan minyak sebagai berikut.

Tabel 1 Nilai Index Oil Spill Index

\begin{tabular}{ccccc}
\hline \multicolumn{5}{c}{ Oil Spill Index } \\
\hline 0.23 & 0.39 & 0.38 & 0.38 & 0.35 \\
\hline 0.40 & 0.40 & 0.40 & 0.33 & 0.33 \\
\hline 0.22 & 0.40 & 0.40 & 0.37 & 0.33 \\
\hline 0.35 & 0.39 & 0.41 & 0.41 & 0.35 \\
\hline 0.35 & 0.36 & 0.41 & 0.41 & 0.37 \\
\hline
\end{tabular}

Pengolahan citra Oil Spill Index dengan matriks $5 \times 5$ yang memperoleh nilai baru pada Tabel 1. Terdapat 25 piksel yang memiliki nilai yang berbeda yaitu 14 pixel merupakan nilai yang layak sebagai tumpahan minyak dan 11 piksel merupakan nilai yang tidak layak sebagai tumpahan minyak. Titik piksel yang layak adalah 1 sesuai dengan nilai Oil Spill Index tumpahan minyak berkisar pada 0.38-0.42. Nilai yang tidak termasuk tumpahan minyak dinyatakan dengan nilai 0 .

Tabel 2. Perhitungan Oil Spill Index

\begin{tabular}{ccccc}
\hline \multicolumn{7}{c}{ Oil Spill Index $30 \times 30 ~ m$} \\
\hline 0 & 1 & 1 & 1 & 0 \\
\hline 1 & 1 & 1 & 0 & 0 \\
\hline 0 & 1 & 1 & 0 & 0 \\
\hline 0 & 1 & 1 & 1 & 0 \\
\hline 0 & 0 & 1 & 1 & 1 \\
\hline
\end{tabular}

Nilai piksel Citra Oil Spill Index :

$0+1+1+1+0+1+1+1+0+0+0+1+1+0+0+0+1+1+1+0+0+0+1+1+1$

$=14$

Jadi, Luas Tumpahan minyak dengan Oil Spill Index = Nilai Piksel pada citra X Resolusi spasial Landsat $8\left(\mathrm{~m}^{2}\right)$

Oil Spill Index $=14 \times 900 \mathrm{~m}^{2}$

Oil Spill Index $=12.600 \mathrm{~m}^{2}$

Oil Spill Index $=1,26$ Hektar

Tabel 3. Perkiraan Luas Sebaran Tumpahan Minyak

\begin{tabular}{lcc}
\hline Kategori & Oil Spill Index & Algoritma Thresholding \\
\hline Light Oil & 1983.51 Hektar & 1696.32 Hektar \\
\hline Medium Oil & 2105.28 Hektar & 3457.44 Hektar \\
\hline Heavy Oil & 3592.17 Hektar & 2665.89 Hektar \\
\hline Total Luas Tumpahan Minyak & 7680.96 Hektar & 7819.65 Hektar \\
\hline
\end{tabular}

Uji akurasi algoritma terhadap tumpahan minyak dilakukan dengan membandingkan hasil luas data lapangan dengan hasil pengolahan citra. Luas data lapangan sebesar $\pm 200 \mathrm{~km}^{2}$ [2].

Persentase $=100 \% \times($ L2-L1 $) / L 2$

dimana,

L1 : Luas pemukaan air danau dari data resolusi menengah dalam satuan meter $\left(\mathrm{km}^{2}\right)$

Aplikasi Deteksi Tumpahan Minyak dengan Interpretasi Citra Satelit Landsat 8 
L2 : Luas permukaan air danau dari data resolusi tinggi (Luas referensi) dalam satuan meter $\left(\mathrm{km}^{2}\right)[12]$. Proses perhitungan persentasi uji akurasi algoritma tumpahan minyak sebagai berikut.

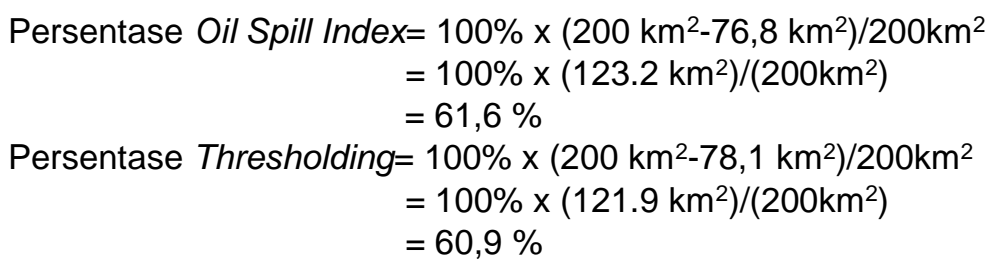

Berdasarkan hasil uji akurasi dapat diketahui bahwa algoritma Oil Spill Index dengan nilai total akurasi 61,6 \% dan hasil uji akurasi dengan algoritma Thresholding dengan nilai total akurasi $60.9 \%$. Uji akurasi tersebut tidak terlalu tinggi, hal ini kemungkinan disebabkan karena perbedaan pengambilan data lapang dengan waktu perekaman citra sehingga tumpahan minyak dapat berpindah tempat akibat terbawa arus laut dan juga data lapang yang terbatas.

\section{Kesimpulan}

Perancangan aplikasi deteksi luas tumpahan minyak memiliki tiga proses utama yaitu pemotongan citra, komposit false color dan analisis untuk perhitungan luas dengan algoritma Thresholding dan Oil Spill Index. Hasil Uji coba membuktikan aplikasi dapat mendeteksi tumpahan minyak dan menghasilkan persebaran serta luas tumpahan minyak. Penggunaan algoritma Thresholding dan Oil Spill Index menghasilkan selisih luas tumpahan minyak yang tidak terlalu besar. Persentase akurasi hasil luas tumpahan minyak yang diperoleh dari perhitungan menggunakan algoritma Thresholding sebesar 61,6\% sedangkan perhitungan dengan algoritma Oil Spill Index menghasilkan 60,9\%.

\section{DAFTAR PUSTAKA}

[1]. Subdirektorat Statistik Lingkungan Hidup. Statistik Lingkungan Hidup Indonesia. Badan Pusat Statistik. Nomor Report:04320.1601.2016

[2]. Maryani Hartuti., Litbang Pemanfaatan Data Radar Untuk Pesisir Dan Laut. Pusat Pemanfaatan Penginderaan Jauh.LAPAN.2015:19

[3]. Thomas Lillesand, R.W. Kiefer, Jonathan Chipma.Remote Sensing And Image Interpretation,New York: Wiley; 7 edition.

[4]. K. G. Kurniadi, I. P. A. Bayupati, I. D. Nyoman, and N. Putra, "Aplikasi Penghitungan Gross Primary Production dari Data Penginderaan Jauh,” e-journal LONTAR Komput, 2016,7(1), pp. 706-714,.

[5]. Qianguo Xing, Lin Li,Mingjing Lou, Observation of Oil Spills through Landsat Thermal Infrared Imagery: A Case of Deepwater Horizon.Aquatic Procedia. 2015. Vol 3 (151 - 156).

[6]. S.H.Kusumo.,N.K.A.Wirdiani.,I.G.M.A.Sasmita.Aplikasi Analisa Perubahan Penggunaan Lahan di Provinsi Bali. MERPATI.2016:4(3):225

[7]. Muhammad Sudibjo, V. P. Siregar, Jonson Lumban Gaol, Algoritma Untuk Deteksi Tumpahan Minyak Di Laut Timor Menggunakan Citra Modis, Jurnal Teknologi Perikanan dan Kelautan. 2013.4(1):41-62. Institut Pertanan Bogor

[8]. $\quad$ PUSFATJA. Pedoman Pengolahan Data Penginderaan Jauh Landsat 8 untuk MPT, LI 103 00709 01:LAPAN.2015:6.

[9]. $\quad$ Aishwarya S., Jayageetha R.T., Leninisha S.Oil Spill Detection Using Optimal Thresholding for MODIS Images, 2014, IJAREEIE.3(2):15

[10]. Dessi, F, Melisa, Naitzaa L, and A Mariana, Modis Data Processing For Coastol and Marine Environment Monitoring: a study on anomaly detection and evolution In gulf of Cagliari (Sardiania Italy). 2013. The International Archives of the Photogrammetry, Remote Sensing and spatial Information Sciences. (37):695-698

[11]. A.A.Alesheikh, S. G. Shahini, Assesment of Spectral Analysis Methods to Detect and Monitor Oil Spill Using MODIS Data. 2015, SASTECH. 4:4.

[12]. Rokhis Khomarudin.Pedoman Pemantauan Perubahan Luas Permukaan Air Danau Meng gunakan Data Satelit Penginderaan Jauh, LI1020010101: LAPAN.2015:9. 
